\title{
Effect of Educational Progressive Web Application on Patient's Oral and Denture Knowledge and Hygiene: A Randomised Controlled Trial
}

\section{Jade Yi Ming Ng}

Universiti Kebangsaan Malaysia

\section{Tong Wah Lim}

Universiti Teknologi MARA

Natasya Tarib

KPJ Tawakkal Health Centre

Ting Khee Ho ( $\nabla$ tingkhee.ho@ukm.edu.my )

Universiti Kebangsaan Malaysia https://orcid.org/0000-0002-2633-3394

Research article

Keywords: Mobile application, Dental health education, Removable partial denture, Dental plaque, Oral health, Oral hygiene

Posted Date: June 22nd, 2020

DOl: https://doi.org/10.21203/rs.3.rs-35939/v1

License: (9) This work is licensed under a Creative Commons Attribution 4.0 International License. Read Full License 


\section{Abstract}

Background: Patient dental education is crucial for the prevention of oral diseases. Effective conveyance of post-denture delivery instructions is beneficial for promoting good oral and denture hygiene. This study aimed to evaluate the effect of a novel progressive web application (PWA) on the patient's oral and denture knowledge and hygiene. The patient's acceptance of this new educational approach was also assessed.

Methods: A parallel randomised controlled trial was conducted at the Faculty of Dentistry, Universiti Kebangsaan Malaysia. A total of 52 cobalt-chromium removable partial denture wearers aged 25-75 years were randomised into two groups. The participants in the PWA group were educated using PWA, whereas those in the control group were educated verbally, accompanied by a practical demonstration of hygienic procedures. A questionnaire was provided to evaluate the changes in the participants' knowledge score at baseline, immediately after education and at 3 months after education. A blinded single examiner conducted the clinical assessment of plaque index $(\mathrm{PI})$, gingival index $(\mathrm{GI})$ and denture plaque (DP) scores at baseline $\left(D_{0}\right)$ and at 1 month $\left(D_{30}\right)$ and 3 months after education $\left(D_{90}\right)$. The patients' acceptance of PWA was explored through usage logs and a feedback form. Data were analysed using two-way mixed ANOVA, Mann-Whitney $U$ test and Friedman test.

Results: A total of 49 participants were analysed. The PWA and control groups showed significant improvement in knowledge scores and oral and denture hygiene indices $(p<0.001)$ after education. The PWA group demonstrated lower $\mathrm{PI}, \mathrm{GI}$ and $\mathrm{DP}$ scores than the control group at $\mathrm{D}_{30}$ and $\mathrm{D}_{90}$. However, only the $\mathrm{GI}$ was significantly lower $(p=0.008)$ at $D_{90}$. In addition, $92 \%$ of the participants used PWA at least once after being introduced to it.

Conclusions: PWA was effective in improving the patients' oral and denture knowledge and hygiene. The participants also found it as a useful reference material for denture care. Thus, PWA is a viable option for providing post-denture delivery instructions.

Trial registration: ClinicalTrials NCT04358172. Retrospectively registered on 21/04/2020. https://clinicaltrials.gov/ct2/show/NCT04358172

\section{Background}

Patient dental education is vital for the promotion of good oral health, especially in removable partial dentures (RPD) wearers who are at increased risk of developing caries and periodontitis [1]. However, a high percentage of patients reported not receiving denture hygiene instructions post-denture delivery [2, 3]. Unsurprisingly, investigations on the knowledge and levels of denture hygiene amongst patients are generally unsatisfactory $[4,5]$.

Different levels of knowledge about denture hygiene maintenance amongst dental practitioners lead to conflicting instructions about denture cleansing methods, resulting in the ineffective conveyance of post- 
denture delivery instructions. Some of them have an unfavourable attitude in educating patients, especially the elderly [6]. Supplementing verbal education with written instructions improves the patient's denture hygiene [5]. Patients are more likely to recall and practise the guidelines for denture care when provided with printed educational materials that contain illustrations $[7,8]$.

However, printed materials also have disadvantages [9], which may be solved using mobile applications [10]. The main types of mobile applications are native, web and hybrid applications [11]. Progressive web application (PWA) was introduced in 2015 as a new approach to mobile application development [12]. Its user-interface design and navigation are similar to those of native application, but it is more affordable to develop and maintain. Thus, PWA is gaining popularity for mobile application construction [13].

The mobile applications used in educating and motivating orthodontic patients to practise good oral hygiene showed excellent results [14-16]. Thus, they could be potentially used as a tool for chairside education and a take-home reference material for partial denture wearers. The present study aimed to evaluate the effect of a newly developed educational PWA on RPD wearers' oral and denture knowledge and hygiene compared with that on the control group who received verbal instructions with demonstrations. Furthermore, their acceptance of this new educational approach was evaluated.

\section{Methods}

\section{Study design}

A prospective, parallel randomised controlled trial was conducted on 52 cobalt-chromium RPD participants at the Faculty of Dentistry, Universiti Kebangsaan Malaysia (UKM), from August 2019 to November 2019. Ethical approval was obtained from the UKM Ethics Committee [UKM PPI/111/8/JEP2018-583] before the commencement of the study.

The sample size was calculated based on the primary outcome measure, which is the change in the knowledge test score. A minimal sample size of 36 subjects was required on basis of an effect size of 0.4 derived from a previous study [15], with significance levels of $5 \%$ and $80 \%$. A total of 52 subjects were recruited to allow for potential dropout rates of $40 \%$.

A random number generator [17] was used to assign unique identification numbers to the participants, who were then allocated equally into the PWA and control groups via a random sequence generator software [18]. The participants' allocation group was concealed in sealed brown envelopes labelled with their identification numbers by a research assistant who was not involved in the data collection nor analysis. The study was single-blind, whereby the participant's allocation was kept anonymous from the outcome assessor.

\section{Eligibility criteria}

The inclusion criteria included patients wearing cobalt-chromium RPD made at the dental laboratory in UKM and delivered by undergraduate students from June 2017 to June 2019 in UKM, patients who own a 
smartphone with Internet access and have been using it within the last 6 months, patients aged 25-75 years and patients who are literate in English or Malay language.

The exclusion criteria included patients who do not wear their RPDs or only wear them occasionally; patients with a history of denture repair or reline and those using denture adhesive; patients with physical or mental disabilities that impede their ability to perform oral hygiene activities; patients involved in other oral-health education or oral hygiene maintenance program; active smokers and patients with medical conditions that may affect their gingival health, such as drug-induced gingival hypertrophy or xerostomia.

\section{Intervention}

The participants were educated by two trained research assistants using the PWA or the conventional method practised by the undergraduates at the Faculty of Dentistry, UKM. In the PWA group, the research assistant explained the PWA contents to the participants after a guided installation (Additional file 1) was provided. In the control group, the participants were educated verbally, accompanied by a practical demonstration of hygienic procedures on dental models. A checklist was provided to both research assistants to ensure consistency when employing the conventional method.

The PWA evaluated in this study was named 'Oral and Denture Guide'. It was created on Angular JavaScript 4.0 using GoodBarber, which is an application builder [19]. The development of this PWA was based on user-centred design principles [20]. It was validated using a mixed-method approach consisting of expert assessment of content and design and user involvement [21]. The final layout of the PWA after refinement (Fig 1.) was pilot tested before the study.

The 'Oral and Denture Guide' PWA has a bilingual content consisting of recommended essential postdenture delivery information [8] and videos on oral and denture hygiene procedures. The evidence-based written details were accompanied by pictures to improve understanding. All the pictures and videos in the PWA were produced by the authors. Given that the end-users included the elderly, the authors paid attention to font selection and user interface design to enhance the usability of this application [22].

\section{Outcome assessment}

The participants' knowledge was measured using a self-administered questionnaire before education $\left(T_{0}\right)$, after education during the same visit $\left(T_{1}\right)$ and 3 months after the first visit $\left(T_{2}\right)$. The developed and validated questionnaire was used to collect the participants' demographic data and test their knowledge of denture care and hygiene (Additional file 2). Pilot test was conducted to gauge the suitability of the questions and the average knowledge score. One mark was given for every correct answer, whilst zero was given for every wrong answer and 'Not sure'.

Silness and Loe's plaque index (PI) [23] and gingival index (GI) [24] were used to evaluate the participants' oral hygiene. A single examiner calibrated the indices before the study, with intra-examiner kappa values of 0.814 for $\mathrm{PI}$ and 0.826 for $\mathrm{Gl}$. The same operator examined all the participants at baseline $\left(\mathrm{D}_{0}\right), 1$ 
month after education $\left(D_{30}\right)$ and 3 months after education $\left(D_{90}\right)$. The plaque and gingivitis levels on the buccal, lingual, mesial, and distal tooth surfaces of all teeth were recorded to obtain the overall mean value. When in doubt between two scores, the higher score was chosen. The index for each participant was obtained by summing the scores divided by the number of teeth present.

Denture plaque (DP) scores were measured to assess the denture hygiene amongst participants. The fitting surface of the RPDs were stained using GC Tri Plaque ID Gel plaque disclosing agent (GC Corporation, Japan) following the methods described by Jeganathan et al [25]. The research assistant then placed each RPD in a photo lightbox and took coloured photographs by using a digital single-lens reflex camera (Nikon D5600, Japan) mounted on a camera stand. The RPDs were subsequently cleaned in an ultrasonic cleaner using Biosonic Enzymatic Ultrasonic Cleaner (Coltene, Japan) and returned to the participants. The blinded single examiner superimposed gridlines measuring $0.5 \mathrm{~cm} \times 0.5 \mathrm{~cm}$ on the photographs of the RPD and examined them in the computer screen under a magnification of $200 \%$. The scoring criteria were as follows: $0=$ no plaque, 1 = light plaque ( $25 \%$ of the fitting surface was covered), 2 $=$ moderate plaque $(26 \%-50 \%$ of the fitting surface was covered), $3=$ heavy plaque $(51 \%-75 \%$ of the fitting surface was covered) and $4=$ very heavy plaque $(76 \%-100 \%$ of the fitting surface was covered) [25]. For patients wearing maxillary and mandibular RPDs, the higher score between the two was recorded. The intra-examiner reliability test performed to $10 \%$ of the participants at $D_{0}, D_{30}$ and $D_{90}$ had kappa values of $0.688,0.722$ and 0.706 , respectively, indicating good agreement.

\section{Acceptance of the 'Oral and Denture Guide' PWA}

The actual usage of the PWA was investigated using objective and subjective measures to assess the patient's acceptance [26]. The objective measure included the usage logs generated by the software in the form of PWA traffic, whilst the subjective measure consisted of the feedback form administered to the participants in the PWA group during the third visit. The study procedure and data collection are displayed in Fig. 2.

\section{Statistical analyses}

The data collected were explored and analysed on SPSS (version 26, IBM). The participants' demographic characteristics were summarised using descriptive statistics. The effect of PWA on the knowledge scores compared with that of the conventional method of education was analysed using two-way mixed ANOVA. For ordinal data, differences in the PI, GI and DP scores between the PWA group and the control group at all three visits were determined using the Mann-Whitney $U$ test. Friedman test was conducted to analyse the changes in baseline $\mathrm{PI}, \mathrm{Gl}$, and DP scores within each group after exposure to education. The level of significance was set at $p<0.05$.

\section{Results}

The 52 participants allocated to the PWA and control groups did not show any significant difference in terms of demographic factors (Table 1). Three participants failed to return for the third-month review, and 
$50 \%$ of the remaining 24 participants in the PWA group were aged 60 years and above.

Table 1

Patients' demographic data at baseline

\begin{tabular}{|c|c|c|c|}
\hline Characteristics & PWA $(n=26)$ & Control $(n=26)$ & p-value \\
\hline Sex, n (\%) & $11(42.3)$ & $10(38.5)$ & $0.777^{*}$ \\
\hline Male & $15(57.7)$ & $16(61.5)$ & \\
\hline \multicolumn{4}{|l|}{ Female } \\
\hline Race, n (\%) & $14(53.8)$ & $16(61.5 \%)$ & \multirow[t]{4}{*}{$0.802^{\dagger}$} \\
\hline Malay & $7(26.9)$ & 7 (26.9) & \\
\hline Chinese & $5(19.2)$ & $3(11.5)$ & \\
\hline \multicolumn{3}{|l|}{ Indian } & \\
\hline Age (years) & $55.42(11.68)$ & $56.27(12.40)$ & \multirow[t]{8}{*}{$0.801^{\wedge}$} \\
\hline Mean (SD) & 0 & 1 & \\
\hline Range $<30$ & 3 & 3 & \\
\hline $30-39$ & 5 & 3 & \\
\hline $40-49$ & 6 & 7 & \\
\hline $50-59$ & 8 & 9 & \\
\hline $60-69$ & 4 & 3 & \\
\hline \multicolumn{3}{|l|}{$\geq 70$} & \\
\hline Education level, n (\%) & $0(0)$ & $3(11.5)$ & \multirow[t]{4}{*}{$0.141^{\dagger}$} \\
\hline Primary & $15(57.7)$ & $17(65.4)$ & \\
\hline Secondary & $11(42.3)$ & $6(23.1)$ & \\
\hline \multicolumn{3}{|l|}{ Tertiary } & \\
\hline Occupation, n (\%) & $5(19.2)$ & $6(23.1)$ & \multirow[t]{5}{*}{$0.256^{\dagger}$} \\
\hline Civil servant & $11(42.3)$ & 7 (26.9) & \\
\hline Private sector worker & $2(7.7)$ & 7 (26.9) & \\
\hline Homemaker & $8(30.8)$ & $6(23.1)$ & \\
\hline \multicolumn{3}{|l|}{ Retiree } & \\
\hline \multicolumn{4}{|c|}{ * indicates $p$-value derived from Chi-square test. } \\
\hline$\dagger$ indicates $p$-value de & d from Fische & exact test. & \\
\hline
\end{tabular}


${ }^{\wedge}$ indicates p-value derived from independent t-test.

\section{Knowledge Scores}

The results of the two-way mixed ANOVA showed no significant difference in mean knowledge scores ( $F$ $=0.007, p=0.934$ ) between the PWA group and the control group at $T_{0}, T_{1}$ and $T_{2}$. However, the knowledge scores changed significantly after exposure to education in both groups $(F=195.062, p<$ 0.001). Pairwise comparison with Bonferroni correction revealed a significant difference $(p<0.001)$ in knowledge scores at all time intervals, as displayed in the graph in Fig. 3.

Given that $50 \%$ of the participants in the PWA group were seniors, further investigation was conducted to compare the knowledge scores between the PWA participants below 60 years of age and those aged 60 years and above. Mann-Whitney $U$ test was used for intergroup comparison, because the data were not normally distributed. No significant difference was observed in the mean rank knowledge score between the two age groups at $T_{0}(p=0.319), T_{1}(p=0.319)$ and $T_{2}(p=0.590)$. By contrast, intragroup comparison using Friedman test showed a significant improvement in the mean rank knowledge score in both age groups after they were educated $(p<0.001)$.

\section{Pi, Gi And Dp Scores}

Table 2 displays the statistical analysis of the intergroup and intragroup comparisons of $\mathrm{PI}, \mathrm{GI}$ and DP scores. 
Table 2

Intergroup and intragroup comparisons of $\mathrm{Pl}, \mathrm{GI}$ and DP scores

\begin{tabular}{|c|c|c|c|c|}
\hline $\begin{array}{l}\text { Measured } \\
\text { outcome }\end{array}$ & $\begin{array}{l}\text { Baseline, } D_{0}{ }^{a} \\
\text { Mean (SD) } \\
\text { Median (min, } \\
\text { max) }\end{array}$ & $\begin{array}{l}\text { One month, } \mathrm{D}_{30} \mathrm{~b} \\
\text { Mean (SD) } \\
\text { Median (min, } \\
\text { max) }\end{array}$ & $\begin{array}{l}\text { Three months, } D_{90} \\
c \\
\text { Mean (SD) } \\
\text { Median (min, max) }\end{array}$ & p-value \\
\hline PI score & & & & \\
\hline $\begin{array}{l}\text { Control } \\
(n=25)\end{array}$ & $\begin{array}{l}0.82(0.31) \\
0.82(0.1,1.47)\end{array}$ & $\begin{array}{l}0.36(0.27) \\
0.28(0.02,1.12)\end{array}$ & $\begin{array}{l}0.23(0.13) \\
0.21(0.06,0.52)\end{array}$ & $\begin{array}{l}<0.001^{\wedge \wedge} \\
a>b, p< \\
0.001^{\star} \\
a>c, p< \\
0.001^{\star} \\
b>c, p=0.774\end{array}$ \\
\hline $\begin{array}{l}\text { PWA } \\
(n=24)\end{array}$ & $\begin{array}{l}0.85(0.31) \\
0.90(0.07,1.54)\end{array}$ & $\begin{array}{l}0.21(0.09) \\
0.21(0.05,0.35)\end{array}$ & $\begin{array}{l}0.18(0.12) \\
0.16(0.03,0.54)\end{array}$ & $\begin{array}{l}<0.001^{\wedge \wedge \star} \\
a>b, p< \\
0.001^{\star} \\
a>c, p< \\
0.001^{\star} \\
b>c, p=0.582\end{array}$ \\
\hline p-value & $0.653^{\wedge}$ & $0.055^{\wedge}$ & $0.128^{\wedge}$ & \\
\hline GI score & & & & \\
\hline $\begin{array}{l}\text { Control } \\
(n=25)\end{array}$ & $\begin{array}{l}0.57(0.28) \\
0.55(0.12,1.19)\end{array}$ & $\begin{array}{l}0.23(0.15) \\
0.20(0.06,0.62)\end{array}$ & $\begin{array}{l}0.17(0.09) \\
0.17(0.03,0.38)\end{array}$ & $\begin{array}{l}<0.001^{\wedge \wedge \star} \\
a>b, p< \\
0.001^{\star} \\
a>c, p< \\
0.001^{\star} \\
b>c, p=0.609\end{array}$ \\
\hline
\end{tabular}

${ }^{\wedge}$ indicates $\mathrm{p}$-value derived from Mann-Whitney test.

${ }^{\wedge}$ indicates $p$-value derived from Friedman test.

* indicates statistical significance.

Both groups revealed a statistically significant reduction $(p<0.001)$ in the $\mathrm{PI}$ and $\mathrm{Gl}$ scores from $\mathrm{D}_{0}$ to $D_{30}$ and from $D_{0}$ to $D_{90}$. The GI scores at $D_{90}$ was significantly lower in the PWA group than in the control group $(p=0.008)$. No significant difference was found in the median DP scores between the two groups after they were educated $(p=0.175)$. 


\begin{tabular}{|c|c|c|c|c|}
\hline $\begin{array}{l}\text { Measured } \\
\text { outcome }\end{array}$ & $\begin{array}{l}\text { Baseline, } \mathrm{D}_{0} \mathrm{a} \\
\text { Mean (SD) } \\
\text { Median (min, } \\
\text { max) }\end{array}$ & $\begin{array}{l}\text { One month, } \mathrm{D}_{30} \mathrm{~b} \\
\text { Mean (SD) } \\
\text { Median (min, } \\
\text { max) }\end{array}$ & \multicolumn{2}{|l|}{$\begin{array}{l}\text { Mean (SD) } \\
\text { Median (min, max) }\end{array}$} \\
\hline $\begin{array}{l}\text { PWA } \\
(n=24)\end{array}$ & $\begin{array}{l}0.62(0.36) \\
0.67(0.06,1.53)\end{array}$ & $\begin{array}{l}0.17(0.09) \\
0.16(0.02,0.39)\end{array}$ & $\begin{array}{l}0.11(0.05) \\
0.10(0.03,0.22)\end{array}$ & $\begin{array}{l}<0.001^{\wedge \wedge} \\
a>b, p< \\
0.001^{\star} \\
a>c, p< \\
0.001^{\star} \\
b>c, p= \\
0.028^{\star}\end{array}$ \\
\hline $\mathrm{p}$-value & $0.631^{\wedge}$ & $0.204^{\wedge}$ & \multicolumn{2}{|l|}{$0.008^{\wedge \star}$} \\
\hline \multicolumn{5}{|l|}{ DP score } \\
\hline $\begin{array}{l}\text { Control } \\
(n=25)\end{array}$ & $\begin{array}{l}3.30(0.80) \\
4.00(2.00,4.00)\end{array}$ & $\begin{array}{l}2.90(1.15) \\
3.00(1.00,4.00)\end{array}$ & $\begin{array}{l}2.60(1.23) \\
3.00(1.00,4.00)\end{array}$ & $\begin{array}{l}<0.001^{\wedge \wedge *} \\
a>b, p=0.063 \\
a>c, p< \\
0.001^{\star} \\
b>c, p=0.063\end{array}$ \\
\hline $\begin{array}{l}\text { PWA } \\
(n=24)\end{array}$ & $\begin{array}{l}3.30(0.90) \\
4.00(2.00,4.00)\end{array}$ & $\begin{array}{l}2.70(1.16) \\
3.00(1.00,4.00)\end{array}$ & $\begin{array}{l}2.10(1.02) \\
2.00(1.00,4.00)\end{array}$ & $\begin{array}{l}<0.001^{\wedge \wedge *} \\
a>b, p<0.231 \\
a>c, p= \\
0.003^{\star} \\
b>c, p=0.359\end{array}$ \\
\hline$p$-value & $0.860^{\wedge}$ & $0.510^{\wedge}$ & $0.175^{\wedge}$ & \\
\hline \multicolumn{5}{|c|}{ ^ indicates $p$-value derived from Mann-Whitney test. } \\
\hline \multicolumn{5}{|c|}{$\wedge \wedge$ indicates $p$-value derived from Friedman test. } \\
\hline \multicolumn{5}{|c|}{ * indicates statistical significance. } \\
\hline $\begin{array}{l}\text { Both group } \\
D_{30} \text { and frc } \\
\text { control gro } \\
\text { two groups }\end{array}$ & $\begin{array}{l}\text { a statistically sigr } \\
90 \text {. The GI scores a } \\
\text { 08). No significant } \\
\text { were educated ( } p\end{array}$ & $\begin{array}{l}\text { cant reduction }(p<0 \\
90 \text { was significantly } \\
\text { fference was found } \\
.175) \text {. }\end{array}$ & $\begin{array}{l}\text { 01) in the PI and GI s } \\
\text { ower in the PWA grou } \\
\text { the median DP scor }\end{array}$ & $\begin{array}{l}\text { ores from } D_{0} \text { to } \\
\text { than in the } \\
\text { between the }\end{array}$ \\
\hline
\end{tabular}

'Oral and Denture Guide' PWA actual usage 
A 3-month usage log was generated in the PWA software, starting from the day after the PWA was introduced to the participants. The data analysed showed that in 3 months, an average of two persons used the PWA per day. Each user utilised it around three times. When the patients accessed the PWA, an average of four pages were visited each time.

The feedback forms administered to the 24 participants in the PWA group revealed that $92 \%$ used the PWA at least one time (Fig. 4). Two participants did not use it because they felt that the information obtained during the chairside education was sufficient. For the participants who accessed the PWA, the most common reason was to seek additional information, followed by to refer to details that they have forgotten and to share the content with someone they know or to watch videos in the PWA. The majority of the participants responded that the section on denture care was the most useful, and $75 \%$ of the participants mentioned that they recommended the PWA to someone they know.

\section{Discussion}

This study was conducted strictly on patients who received cobalt-chromium RPD dentures processed at the Faculty of Dentistry, UKM, and delivered by undergraduate students under the supervision of specialists within a 2-year duration. These criteria ensure standardisation in the material and design principles of the RPD, which influences gingival health [27]. A maximum duration of 2 years was selected as older RPDs without adequate postplacement care may have integrity defects [28]. Participants above 75 years were excluded due to possible changes in cognitive function [29] and manual dexterity [30], which may both affect the study outcome.

Most published studies on dental-related mobile applications were native applications. PWA was chosen in the present study because of its multi-platform advantage. Phone operating systems and application stores do not restrict its usage, hence the cost-effective development and distribution [31]. PWA also requires less installation space than native application, thereby addressing user's memory space concern [32]. Although PWA is inferior to native application in terms of its ability to access user contacts or calendar, this extra feature was not necessary in the 'Oral and Denture Guide' PWA.

The scale in the index by Jeganathan et al. is widely used to assess the DP in RPDs $[8,33,34]$ and presents high values of agreement with reliability test [25]. Consistently measuring the distribution of plaque on dentures is difficult to perform by visual inspection alone [35]. Thus, in the present study, dentures images were superimposed with gridlines to aid in scoring, as described in the methodology section earlier. Scoring was conducted by a single examiner to reduce measurement error [35].

To the authors' knowledge, this is the first clinical study to develop and evaluate the efficacy of a mobile application for post-denture delivery education of patients with RPD. The results revealed no significant difference in knowledge gain between the participants in the PWA and control groups. Comparison with previous studies $[7,8]$ on the influence of the method of education on RPD wearers' knowledge was not possible because these studies measured oral hygiene instead of knowledge score as an outcome. 
Considering the participants who installed the PWA had the advantage of having a take-home reference material, their performance was expected to improve during the follow-up test at $T_{2}$. However, the results showed a decline in their knowledge scores compared with that at $T_{1}$, which was a similar trend to that in the control group. This outcome differed from the findings of Marchetti et al., who revealed knowledge gain and retention in participants exposed to mobile application. These positive results were attributed to the periodic reinforcement of oral health education by the mobile application developed in their study [15].

On the contrary, active reminders were not sent to the PWA participants in the current study, because the authors were interested in knowing the actual usage on the basis of the participant's own initiative. Moreover, the study by Marchetti et al. was conducted on adolescents, whereas half of the participants in the present study were seniors. The storage capacity of working memory differs between older (aged 6079 years) and younger (aged 18-25 years) individuals [36]. Furthermore, some processing deficits of the working memory possibly exist in older adults [36], thereby reducing their knowledge scores in the questionnaire.

Despite the drop in the knowledge scores during $T_{2}$, the significant increase in the scores compared with those during $T_{0}$ showed that the PWA was indeed effective in delivering valuable information to the participants. Comparison of knowledge gain between the participants below 60 years of age and those aged 60 years and above revealed no significant difference, indicating that the elderly benefitted from the PWA as much as the younger age group. This finding is encouraging, because it may address the problem of elderly patients receiving insufficient denture care information $[6,37]$.

The participants' oral hygiene was significantly improved by the 'Oral and Denture Guide' PWA compared with that of the control group. This finding was in agreement with the findings from the studies on oralhygiene focused applications $[14,16]$. Although no significant difference was found in the PI score between the PWA and control groups, gingival status may be a more reliable measurement of improvement in oral hygiene [38]. The plaque levels assessed may be misleading, because some participants could be more meticulous with their oral hygiene on the day of measurement, resulting in less plaque.

For denture hygiene, no significant difference was found in the DP scores between the PWA group and the control group. This result differed from that of Ribeiro et al., who reported better denture hygiene in the group provided with written illustrated educational material than in the control group [8]. However, this significant difference only started to become evident at the 6-month and 12-month reviews, whereas the participants in the present research were only followed up for 3 months. Moreover, denture hygiene instructions were repeated when necessary during the review sessions. Thus, Ribeiro et al.'s positive results may be attributed to the periodic reinforcement.

Acceptance is an attitude towards a technology that could influence technology adoption. In the present study, the participants' acceptance of this educational approach was assessed by exploring the actual 
usage [26] and their response to PWA. The usage frequency (Fig. 4) was lower than that obtained by Underwood et al., who reported that $44.8 \%$ of participants used the oral health application of interest two times daily. However, most of them used it for less than a week [10]. Although the reported frequency of use was high, the majority of their participants were aged 7-12 years. Moreover, the data reported were based on self-reported usage, which is a subjective measure, whereas the values reported in the present study includes data from the usage log statistics [26]. Besides, the participants in the present study reported that they mainly used the PWA as a source of reference and found the section on denture care to be most useful, thereby substantiating the role of PWA in conveying post-denture delivery instructions. Considering that elderly people take time to adopt new technologies but do so if they find these technologies beneficial [39], the participants' overall response towards PWA was reasonably good.

This study had some limitations. Some differences may exist amongst the RPDs that possibly influenced the GI scores between the PWA group and the control group. Given that the participants received their RPDs within a 2-year duration, increased surface roughness in old dentures [40] could affect cleanliness. Denture design factors, such as the lingual plate major connector, may affect not only the quantity but also the quality of plaque intraorally; thus, these factors may have considerable effects on gingival health [33].

Besides, the participants were only followed up for 3 months without periodic reinforcement during reviews. Retention of the knowledge gained and improvement in behavioural habits over an extended period were not certain. Moreover, participants may not change their old practises on denture care despite acquiring new knowledge [7]. Thus, the effect of the knowledge gain on their denture hygiene routine is uncertain. The results obtained could not be extrapolated to the general population because the PWA may only be useful to a specific group in the society due to limitations, such as language, literacy and the need for a mobile device with Internet access.

Future studies may incorporate behaviour modification techniques when developing mobile applications and exploring their effect on denture hygiene utilisation and habits. Mobile applications could also be improvised, such as adding a read-out loud function or using comprehensive videos to overcome issues of language and literacy. Mobile applications are expected to be widely used amongst all ages in the society as smartphones gradually replace conventional mobile phones. The results of this study suggested that the elderly are receptive to this new educational approach; thus, mobile application developers should consider them as target users and incorporate design features that are user-friendly for elderly people.

\section{Conclusions}

The 'Oral and Denture Guide' PWA developed in this study was an effective education material, even amongst elderly patients, as reflected by the participants' significant improvement in their oral and denture knowledge and hygiene. This PWA could address the problems discussed in the literature, including the inadequate information received by patients during denture delivery, which is dependent on 
the knowledge, attitude and practise of their dentist. Besides, this PWA could be used as a validated reference material due to the high percentage of patients who do not recall receiving denture hygiene instructions. Furthermore, it is more cost-effective and engaging than traditional information leaflets. Therefore, the 'Oral and Denture Guide' PWA could be considered as an excellent alternative to the conventional methods used for patient education during denture delivery.

\section{Abbreviations}

DP

denture plaque; GI:gingival index, PI:plaque index; PWA:progressive web application; RPD:removable partial denture; and UKM:Universiti Kebangsaan Malaysia.

\section{Declarations}

\section{Ethics approval and consent to participate}

Ethical approval was granted by the Universiti Kebangsaan Malaysia Ethics Committee. The reference number is UKM PPI/111/8/JEP-2018-583. All patients were informed about the study and provided written informed consent.

\section{Consent for publication}

Not applicable

\section{Availability of data and materials}

The datasets generated and/or analysed in this study are available from the corresponding author upon reasonable request.

\section{Competing interests}

The authors declare that they have no competing interests.

\section{Funding}

This study was funded by the Young Researcher Incentive Grant (GGPM-2017-108) by University Kebangsaan Malaysia. Financial support was provided for the maintenance of the progressive web application and printing materials.

\section{Authors' contributions}

All authors substantially contributed to the development of the intervention, study design and data collection and interpretation. TKH supervised the study procedure, whilst JYMN conducted the clinical 
assessments and drafted the initial manuscript. TKH, TWL and NT revised the paper to its final version. All authors read and approved the final manuscript.

\section{Acknowledgements}

The authors would like to acknowledge Dr. Haslina Rani, a Dental Public Health Specialist at the Faculty of Dentistry, UKM, for her input in the validation process of the PWA content. A special thanks to Miss Zaihosnita Hood, a Human-Computer Interaction Expert in UKM, for her contribution in the design evaluation of the PWA's user interface.

\section{References}

1. da F Porto Carreiro, de Carvalho Dias A, Correia Lopes K, Bastos Machado Resende AL. CM, Luz de Aquino Martins AR. Periodontal conditions of abutments and non-abutments in removable partial dentures over 7 years of use. J Prosthodont. 2017;26(8):644-9.

2. Dikbas I, Koksal T, Calikkocaoglu S. Investigation of the cleanliness of dentures in a university hospital. Int J Prosthodont. 2006;19(3):294-8.

3. Cakan U, Yuzbasioglu E, Kurt H, Kara HB, Turunç R, Akbulut A, et al. Assessment of hygiene habits and attitudes among removable partial denture wearers in a university hospital. Niger $\mathrm{J}$ Clin Pract. 2015;18(4):511-5.

4. Ribeiro DG, Jorge JH, Varjão FM, Pavarina AC, Garcia PPNS. Evaluation of partially dentate patients' knowledge about caries and periodontal disease. Gerodontology. 2012;29(2):1-6.

5. Milward P, Katechia D, Morgan MZ. Knowledge of removable partial denture wearers on denture hygiene. Br Dent J. 2013;215(10):1-8.

6. Suresan V, Mantri S, Deogade S, Sumathi K, Panday P, Galav A, et al. Denture hygiene knowledge, attitudes, and practices toward patient education in denture care among dental practitioners of Jabalpur city, Madhya Pradesh, India. J Indian Prosthodont Soc. 2016;16(1):30.

7. Ferruzzi F, Martins JCLS, Mori AA, Santin GC, Kurihara E, Sabio S. Influence of educational materials on the hygiene and utilization habits of denture wearers. Gen Dent. 2015;63(4):e6-10.

8. Ribeiro DG, Pavarina AC, Giampaolo ET, Machado AL, Jorge JH, Sasso Garcia PPN. Effect of oral hygiene education and motivation on removable partial denture wearers longitudinal study. Gerodontology. 2009;26(2):150-6.

9. Renuka P, Pushpanjali K. Leaflet preparation and validation procedures. Univers J Public Heal. 2013;1(3):110-4.

10. Underwood B, Birdsall J, Kay E. The use of a mobile app to motivate evidence-based oral hygiene behaviour. Br Dent J. 2015;219(4):E2.

11. Majchrzak TA, Biørn-Hansen A, Grønli T-M: Progressive Web Apps: the definite approach to crossplatform development? In Proceedings of the 51st Hawaii International Conference on System Sciences: 2018: 5735-44. 
12. Biørn-Hansen A, Majchrzak TA, Grønli TM: Progressive web apps: The possible web-native unifier for mobile development. In Proceedings of the 13th International Conference on Web Information Systems and Technologies (WEBIST 2017): 2017: 344-51.

13. de Andrade Cardieri G, Zaina LM. Analyzing user experience in mobile web, native and progressive web applications: a user and $\mathrm{HCl}$ specialist perspectives. In 17th Brazilian Symposium on Human Factors in Computing Systems (IHC 2018): 22-26 October 2018; Belém, Brazil: 2018: 1-11.

14. Alkadhi OH, Zahid MN, Almanea RS, Althaqeb HK, Alharbi TH, Ajwa NM. The effect of using mobile applications for improving oral hygiene in patients with orthodontic fixed appliances: a randomised controlled trial. J Orthod. 2017;44(3):157-63.

15. Marchetti G, Fraiz FC, Nascimento WM do, Soares GMS, Assunção LR da S. Improving adolescents' periodontal health: evaluation of a mobile oral health app associated with conventional educational methods: a cluster randomized trial. Int J Paediatr Dent. 2018;28(4):410-9.

16. Scheerman JFM, van Meijel $B$, van Empelen P, Verrips GHW, van Loveren C, Twisk JWR, et al. The effect of using a mobile application ("WhiteTeeth") on improving oral hygiene: a randomized controlled trial. Int J Dent Hyg. 2020;18(1):73-83.

17. Random Number Generator [https://stattrek.com/statistics/random-number-generator.aspx] Accessed on 27 July 2019.

18. Random sequence generator software. https://www.graphpad.com/quickcalcs/randomize1/ Accessed on 27 July 2019.

19. GoodBarber. https://www.goodbarber.com/ Accessed on 4 Jun 2020.

20. Harte R, Glynn L, Rodríguez-Molinero A, Baker PM, Scharf T, Quinlan LR, et al. A human-centered design methodology to enhance the usability, human factors, and user experience of connected health systems: a three-phase methodology. JMIR Hum Factors. 2017;4(1):e8.

21. Zaror C, Espinoza-Espinoza G, Atala-Acevedo C, Muñoz-Millán P, Li Y, Clarke K, et al. Validation and usability of a mobile phone application for epidemiological surveillance of traumatic dental injuries. Dent Traumatol. 2019;35(1):33-40.

22. de Barros AC, Leitão R, Ribeiro J. Design and evaluation of a mobile user interface for older adults: navigation, interaction and visual design recommendations. Procedia Comput Sci. 2013;27(2014):369-78.

23. Silness J, Löe H. Periodontal disease in pregnancy II. Correlation between oral hygiene and periodontal condition. Acta Odontol Scand. 1964;22(11):121-35.

24. Löe H, Silness J. Periodontal disease in pregnancy I. Prevalence and severity. Acta Odontol Scand. 1963;21(6):533-51.

25. Jeganathan $S$, Thean HPY, Thong KT, Chan YC, Singh M. A clinically viable index for quantifying denture plaque. Quintessence Int (Berl). 1996;27(8):569-73.

26. Turner $M$, Kitchenham B, Brereton $P$, Charters $S$, Budgen D. Does the technology acceptance model predict actual use? A systematic literature review. Inf Softw Technol. 2010;52(5):463-79. 
27. Bissada NF, Ibrahim SI, Barsoum WM. Gingival Response to Various Types of Removable Partial Dentures. J Periodontol. 1974;45(9):651-9.

28. Hummel SK, Wilson MA, Marker VA, Nunn ME. Quality of removable partial dentures worn by the adult U.S. population. J Prosthet Dent. 2002;88(1):37-43.

29. Mitrushina $M$, Satz P. Changes in cognitive functioning associated with normal aging. Arch Clin Neuropsychol. 1991;6(1-2):49-60.

30. Carmeli E, Patish H, Coleman R. The aging hand. J Gerontol Med Sci. 2003;58A(2):146-52.

31. Rego F, Portela F, Santos MF. Towards pwa in healthcare. Procedia Comput Sci. 2019;160:678-83.

32. Vagrani A, Kumar N, llavarasan PV. Decline in Mobile Application Life Cycle. Procedia Comput Sci. 2017;122:957-64.

33. Zlatarić DK, Čelebić A, Valentić-Peruzović M. The effect of removable partial dentures on periodontal health of abutment and non-abutment teeth. J Periodontol. 2002;73(2):137-44.

34. Yadav AK, Yadav R, Kishlay K, Singh S, Dube P. Periodontal Health Status in RPD Wearing Patients Visiting to Dental Hospital in Azamgarh. J Adv Med Dent Sci Res. 2019;7(10):131-3.

35. Ambjørnsen E, Rise J, Haugejorden O. A study of examiner errors associated with measurement of denture plaque. Acta Odontol Scand. 1984;42(3):183-91.

36. Foos PW. Adult age differences in working memory. Psychol Aging. 1989;4(3):269-75.

37. Papadiochou S, Polyzois G. Hygiene practices in removable prosthodontics: a systematic review. Int J Dent Hyg. 2018;16(2):179-201.

38. Hugoson A, Lundgren D, Asklöw B, Borgklint G. Effect of three different dental health preventive programmes on young adult individuals: a randomized, blinded, parallel group, controlled evaluation of oral hygiene behaviour on plaque and gingivitis. J Clin Periodontol. 2007;34(5):407-15.

39. Vaportzis E, Clausen MG, Gow AJ. Older adults perceptions of technology and barriers to interacting with tablet computers: a focus group study. Front Psychol. 2017;8:1687.

40. Matsumura K, Sato Y, Kitagawa N, Shichita T, Kawata D, Ishikawa M. Influence of denture surface roughness and host factors on dental calculi formation on dentures: a cross-sectional study. BMC Oral Health. 2018;18(1).

\section{Figures}




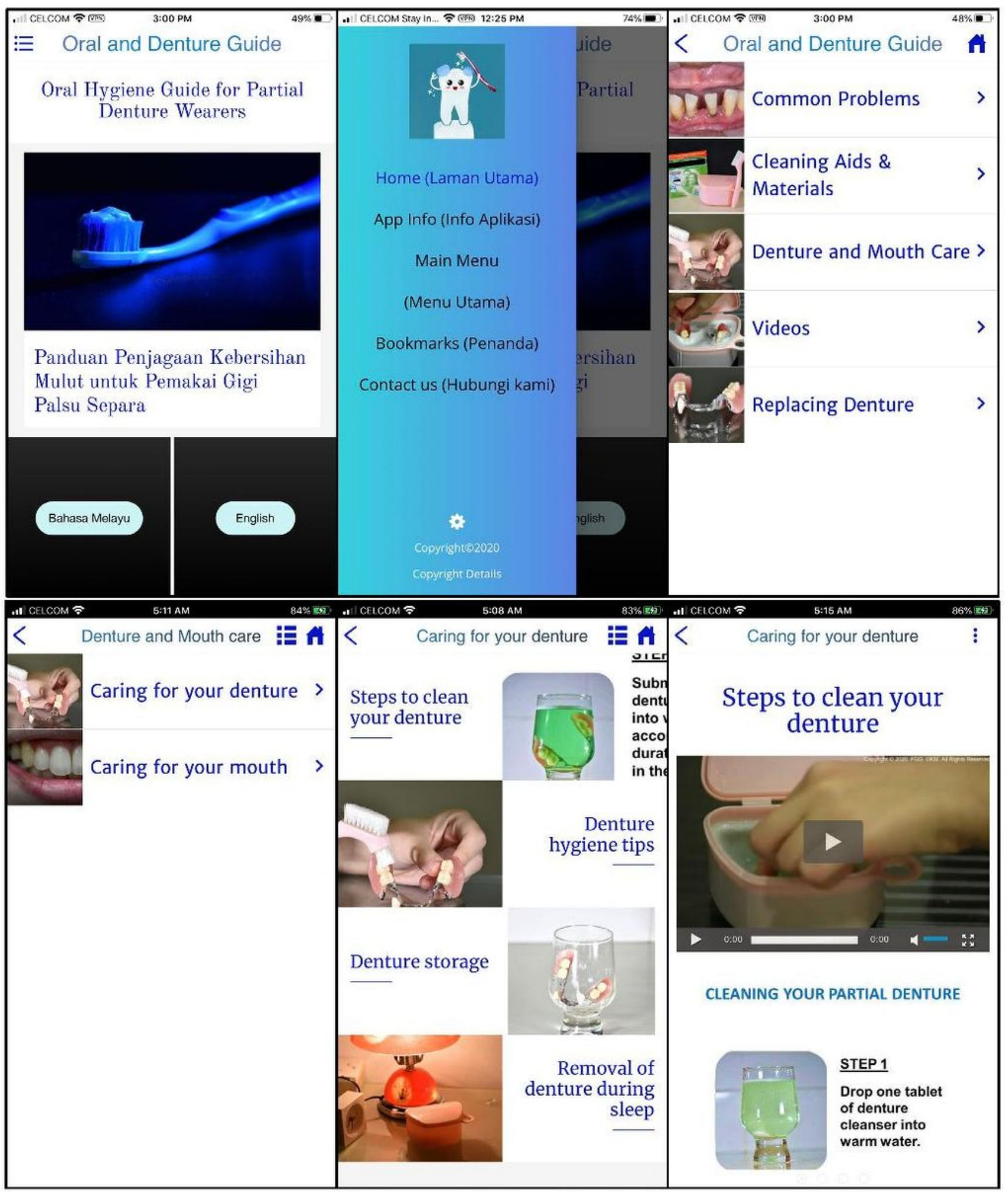

\section{Figure 1}

Final layout of 'Oral and Denture Guide' PWA. Clockwise from top-left: screenshot of homepage, navigation menu, main menu, sub-menu, section displaying a list of topics and article containing illustrations and video. 


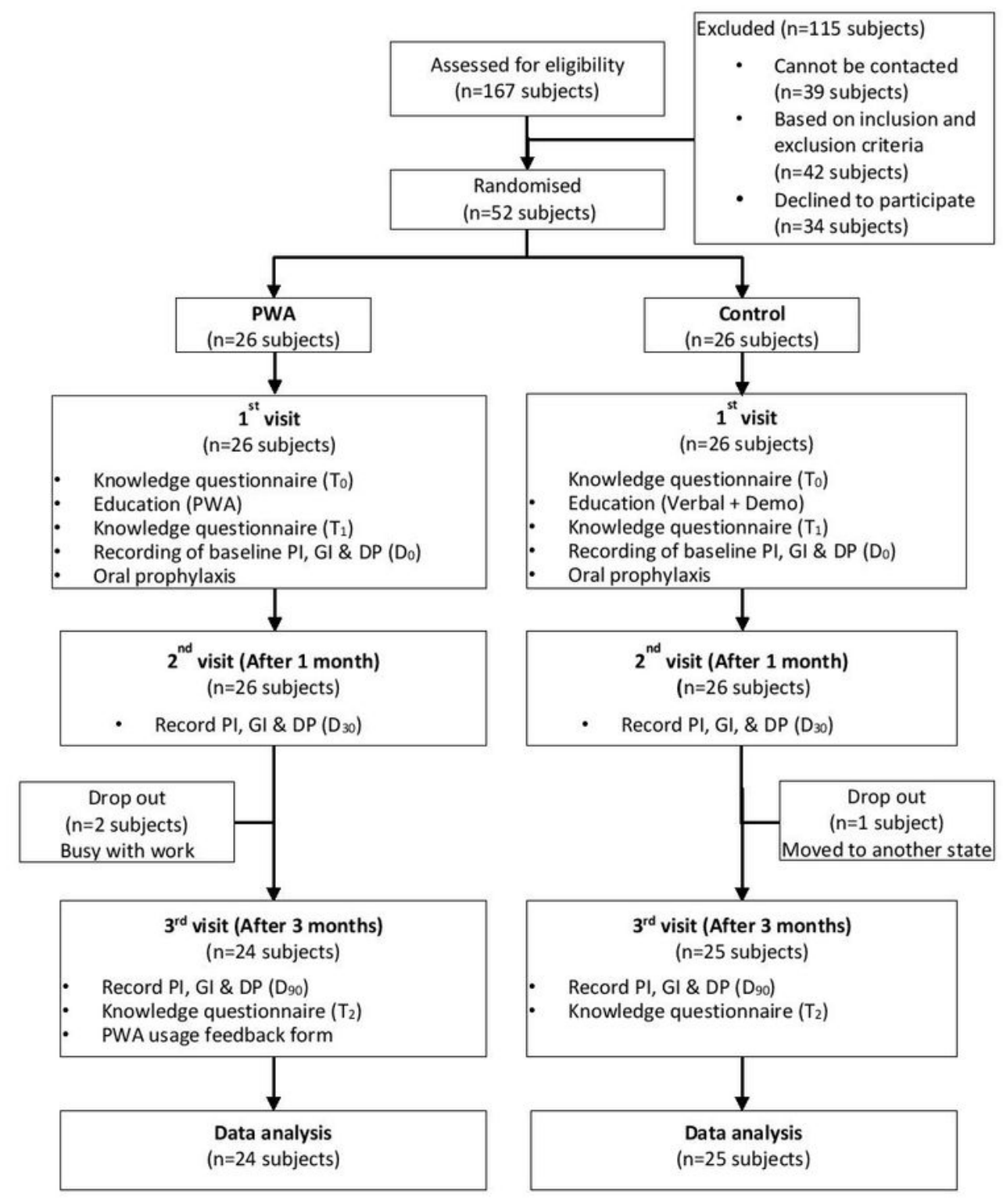

Figure 2

Workflow diagram depicting the study procedure and data collection. 


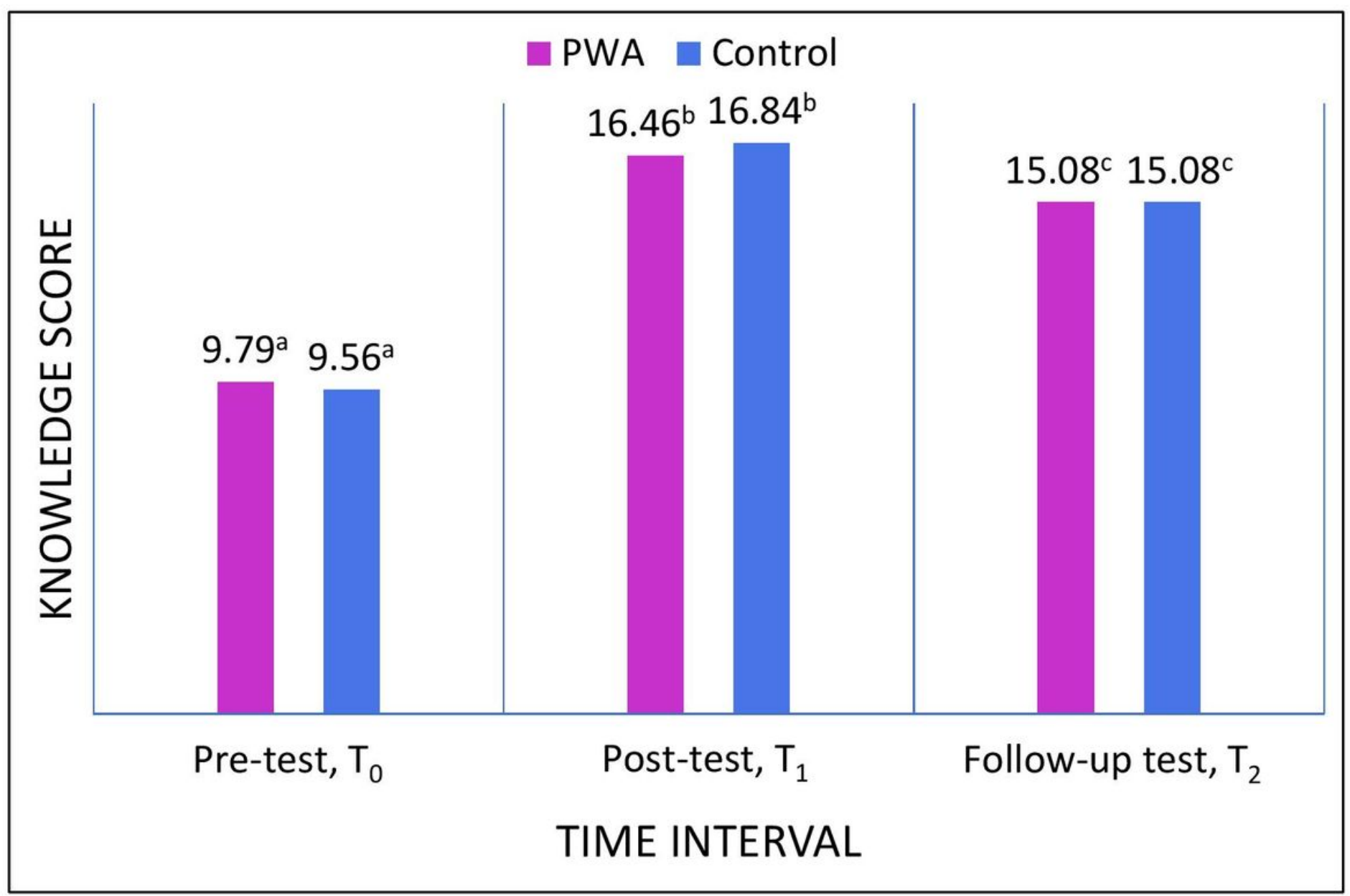

Figure 3

Participants' mean knowledge scores in the PWA and control groups at different time intervals. Means followed by different letters indicate statistically significant differences. 


\section{PWA usage frequency}

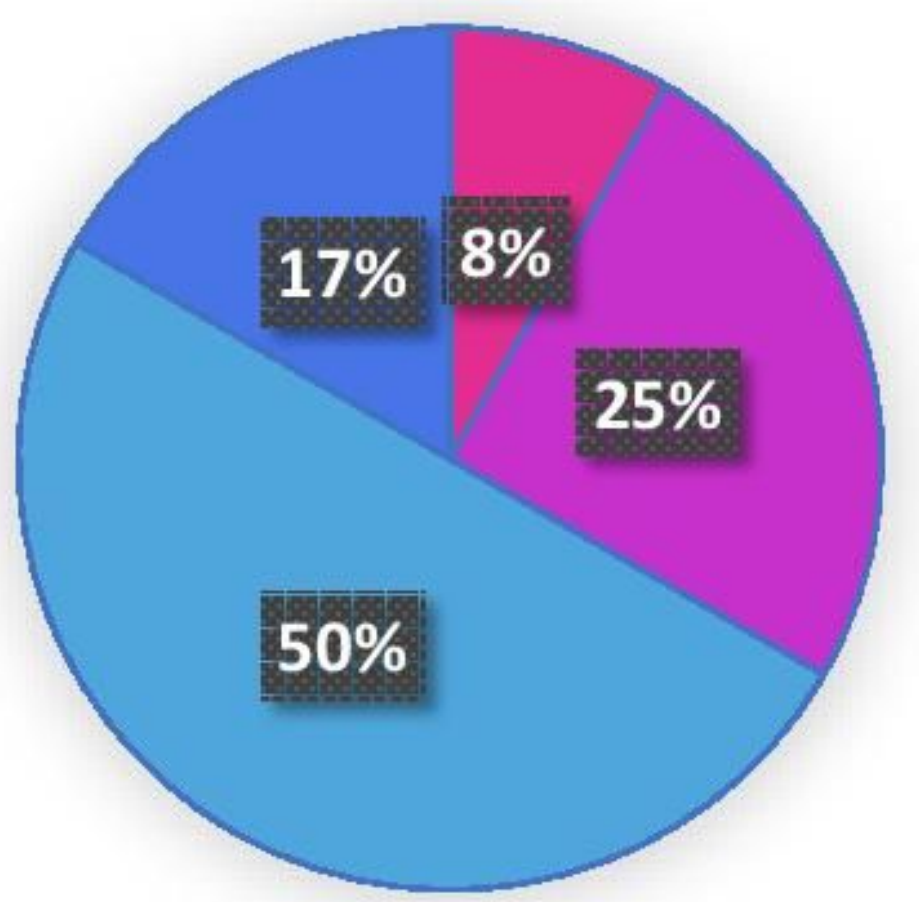

Never

- Once

$\square 2$ to 5 times

$\square>5$ times

\section{Figure 4}

Frequency of PWA usage by the participants. The pie chart shows the percentage of participants using PWA in accordance with the number of times it was used within 3 months.

\section{Supplementary Files}

This is a list of supplementary files associated with this preprint. Click to download.

- Additionalfile2Knowledgequestionnaire.pdf

- Additionalfile1 Installationguide.pdf 